Elsevier's Encyclopædia of Organic Chemistry

Edited by R. Radt. Series 3: Carboisocyclic Condensed Compounds. Vol. 12B : Naphthalene; $A$. Compounds containing One Naphthalene Nucleus; Hydrocarbons and Hal gen Compounds. Pp. xxx+ 344+22. (New Yor and Amsterdam: Elsevier Publishing Co., In (London: Cleaver-Hume Press, Ltd., 1948.) T( subscribers to whole work, $£ 6$ 5s. $0 d$. 7 HIS is actually the first part of vol. $12 B$, for it deals anly with hydrocarbons of the naphthalene serigs, thei hydrides and the halogen compounds. The of ach la ger number of other derivatives, together withdompounds containing more than one naphthalene nucleus, will presumably form the subject of one or more further parts. Series 3 of the 'Encyclopædia' will then be complete, for vols. $12 \mathrm{~A}, 13$ and 14 have already been issued (for a general description of the whole project, see Nature, 161,415 ; 1948). The present volume maintains the standard of excellence of its predecessors ; but the rate of progress is behind schedule, and considerable acceleration will be needed if the work is to constitute an up-to-date compendium of organic chemical compounds.

It is stated in the preface that references up to the end of 1944 have been included in this volume, and, as far as the reviewer has been able to determine, the bibliography is complete. More important publications of 1945-47 are also noted. In addition to its attractive lay-out, the book has many pleasing features, including the useful summaries of data given in many tables, the generous use of neatly printed structural formulæ to illustrate reactions, and the sure chemical instinct exemplified by a number of cogent editorial comments. The sections dealing with the more important compounds, such as naphthalene and its monomethyl and monohalogeno derivatives, tetralin, decalin, cadinene and selinene, form readable and informative articles. The volume may be commended to the attention of all organic chemists, whatever their specific fields of interest.

$$
\text { S. } \quad \text { J. W. Cook }
$$

\section{Géométrie descriptive à quatre dimensions}

Par $J$. Maurin. Livre 1 : Figures du premier degré. Chapitres 1, 2, 3: Définitions, positions, inter1948.) 200 francs.
19etions. Pp. 38. (Pailibr. Gauthier-Villars,

THE reviewer appryached this volume in a mood of reflexion as to the proper place in the general scheme of geometscal study for four-dimensional geometry. His wn introduction to the concepts of geometry of mdrelthan three dimensions was through the excelant volumes of M. Jonffert ("Traité Elémentaire de Géométrie à Quatre Dimensions", 1903 and "Mélanges de Géométrie à Quatre Dimen ons", 1907). Though interested, he felt an acute disappointment in the natural limitations therein, which was not overcome until, long after, Bertini's work came to his hands. He therefore read M. J. Maurin's volume with a prejudice that, for the geometer, the general $n$-dimensional case should be first studied and the four-dimensional enlarged upon later.

M. Maurin, in pointing out the peculiar importance of four-dimensional geometry in the study of some mechanical phenomena, makes a strong case for its independent consideration. The present volume is limited to definitions and the study of the intersections of lines and of planes. His method of presentation is an extension of the method of Monge and is amply illustrated by diagrams which occupy half the volume. The range is too restricted for the reader to obtain any estimate of the ultimate value of the method of approach, but the author suggests that interesting developments will be found in later volumes, which are much looked forward to. In view of his special plea for the importance of fourdimensional study it would have been well if a little more space had been devoted in the introductory pages to initial ideas; the first few paragraphs are so condensed that the student with no previous knowledge will find them insufficient for his understanding.

H. GWYNEDD GreEN

\section{X-Ray Optics}

H.

The Diffraction of X-Rays by Finite and Imperfect Crystals. By A. J. C. Wilson. (Methuen's Monographs on Physical Subjects.) Pp. vii +127. (London : Methuen ang C (., Jod., 1949.) 6s. net.

HIS worlilly maintains the standard that is
now expected from this well-known series. The author fins set himself well-defined limits, has stated these cllirly in the preface, and has treated the sppigct-matter within these limits in a workmanlike fasion. It is unfortunate, therefore, that the main title of the book is deceptive, and that it has to be qualified by a sub-title; a book on X-ray optics should have image formation as its main content; but this subject is not dealt with at all in this book. The author justifies this omission on the grounds that crystal-structure determination is closer to chemistry than to physics. The reviewer does not agree with this; the results are certainly of chemical interest, but the methods are essentially physical.

Apart from the title, however, there is little that one can criticize. The author has collected together a variety of problems in the diffraction of X-rays by imperfect crystals and has shown how they can be treated mathematically. $\mathrm{H}_{\Theta}$ has taken pains to introduce the subject gradually-perhaps too gradually for those who are able to master the later chapters-and therefore almost everybody will gain something from the book. In addition, the style is pleasingly informal. The book can be confidently recommended to those interested in X-ray diffraction, particularly to those concerned with the finer details.

The Way of a Plant in Field and Garden By Gareth H. Browning. Pp. $x+141+7$ plates. (London: Rockliff Publishing Corporation, Ltd., 1949.) 8s. $6 d$. net.

NR. GARTTIP BROWNING, author of several 1 works gr popular natural history, has written another liy book which seeks to explain the func. tions of 10 flowering plant in such a way that it will $\mathrm{A}$ scientifically correct and also intelligible to the ge neral reader. From both points of view he has achieved his object, and his book will be of value to the hon-specialist interested in agriculture, horticulture or the natural history of plants. Whether the book will appeal to them sufficiently to make them want to buy it is another matter. Authors of successful books on popular subjects to-day realize the value of visual appeal and, generally speaking, have set a high standard in the range and quality of the paint. ings, photographs and diagrams of the illustrations to their books. The seven coloured photographs and thirteen line-drawings in "The Way of a Plant" are not enough, neither are they of a high standard.

T. H. H. 